\title{
Tetrapodal ZnO Particles for Substrate Mode Scattering in Flexible Organic Light-Emitting Diodes
}

\author{
Matthias Bremer, ${ }^{1, *}$ Ala Cojocaru, ${ }^{2}$ Iris Hölken, ${ }^{2}$ Ingo Paulowicz, ${ }^{2}$ Markus Köpke, ${ }^{1}$ Rainer Adelung, ${ }^{3}$ \\ Hartmut Schmidt-Niepenberg, ${ }^{2}$ and Martina Gerken ${ }^{1}$ \\ ${ }^{1}$ Institute of Electrical Engineering and Information Technology, University of Kiel, Kaiserstr. 2, 24143 Kiel, Germany \\ ${ }^{2}$ FUMT R\&D Functional Materials GmbH, Kaiserstraße 2, 24143 Kiel, Germany \\ ${ }^{3}$ Institute for Materials Science, University of Kiel, Kaiserstr. 2, 24143 Kiel, Germany \\ *mab@tf.uni-kiel.de
}

\begin{abstract}
A thin polymer foil containing tetrapodal zinc oxide microparticles for volume scattering is produced. This foil is used as bendable substrate for an organic light-emitting diode. OCIS codes: (290.5850) Scattering, particles; (160.5470) Polymers; (230.3670) Light-emitting diodes
\end{abstract}

\section{Introduction}

Organic semiconductors are of high industrial interest for fully flexible organic light-emitting diodes (OLEDs). The high internal OLED efficiencies, which can already go up to 100\%, are lessened by inefficient outcoupling of light with losses in the range of $80 \%$ [1,2]. Half of this loss is due to trapping of light in the substrate, which can be simply explained by a higher refractive index of the substrate $\left(n_{s u b} \approx 1.5\right)$ compared to the surrounding air and Snell's law. On rigid substrates such as glass outcoupling strategies for the trapped mode include surface roughening, the usage of microlenses or spincoating of scattering layers [3,4]. Once changing to flexible materials and using, for example, polymers as substrate material one adds the advantage of being able to mix scattering particles directly into the substrate material and is thereby creating an effective volume scattering [5].

Zink oxide has a wide range of optical, electronic and photonic applications. Depending on the production process you can find different morphologies and sizes of the $\mathrm{ZnO}$ particles: spherical, needle, core-spike particles, hexagonal nanorods, tetrapods, etc [6,7,8]. Zinc oxide particles with tetrapodal morphology (t-ZnO) (Fig. 1) are used in the present work. They are produced by a simple flame transport synthesis approach, developed at the University of Kiel $[7,8]$. Here, we are fabricating foils containing these mircoparticles and processing an OLED on top of them.

\section{Polymer foils with incorporated tetrapodal $\mathrm{ZnO}$ particles}

To produce the t-ZnO particles spherical Zn microparticles material from Sigma Aldrich (purity $>98 \%$, particle size $<10 \mu \mathrm{m})$ are heated to $900{ }^{\circ} \mathrm{C}$ in a crucible with a muffle type furnace under controlled atmosphere for about 10 minutes. The porous white product with low density $\left(<0.1 \mathrm{~g} / \mathrm{cm}^{3}\right)$ can be harvested from the crucible and/or substrates placed above it.
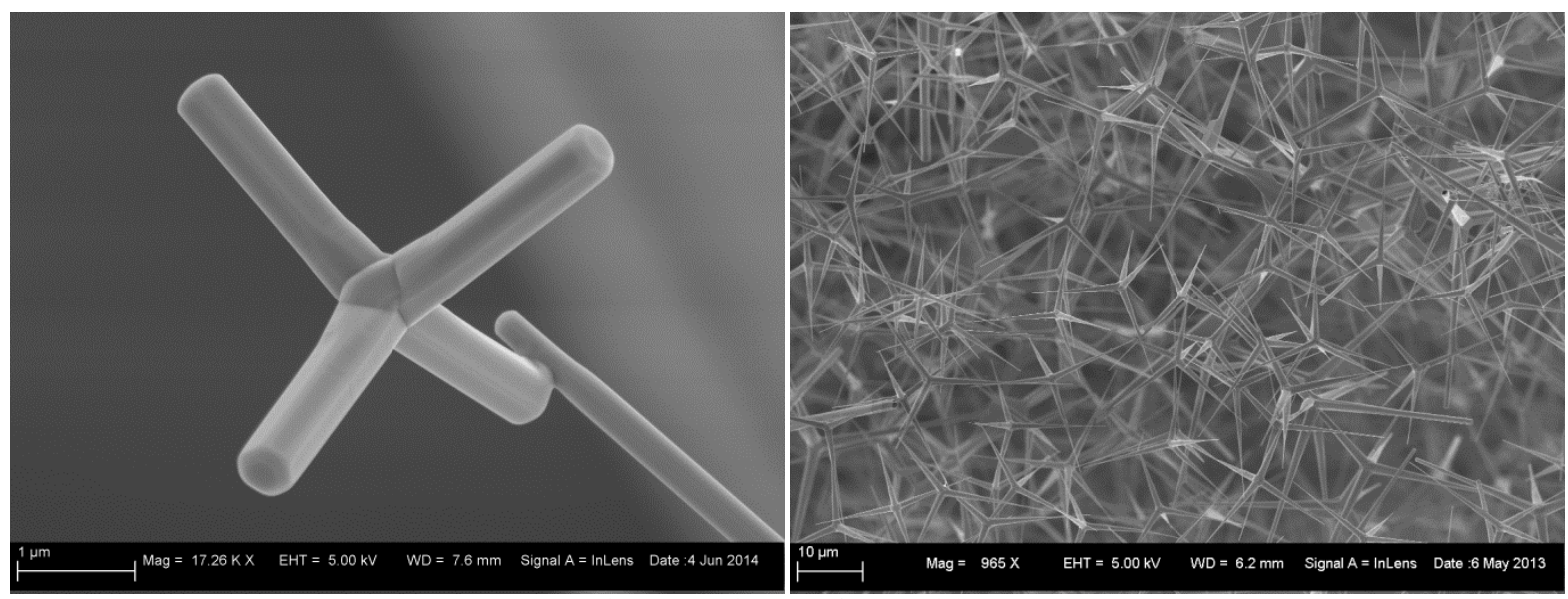

Fig. 1. SEM images of tetrapodal $\mathrm{ZnO}$. 
In a next step the t-ZnO particles are incorporated into a polymer. Here, polythiourethane (PTU) purchased from Fluid- \& Prozesstechnik GmbH (Waltershausen, Germany) is used. PTU is a highly-crosslinked aliphatic thermoset which is obtained by polyaddition of the two components hexamethylene diisocyanate (HDI) and pentaerythritol tetrakis(3-mercaptopropionat) (PETMP) [9]. PTU is absolutely free of solvents, fully transparent in the visible and near infrared spectrum and can be fabricated as thin foil down to a thickness of less than $50 \mu \mathrm{m}$.

Compared to other polymers it has a reasonably low permeability for water and oxygen, but would still need a proper sealing. Weather resistance is given for PTU as it is more stable against ultra violet light exposure than most of the available plastics and already has been used as antifouling coating [9].

In order to obtain PTU substrates, the polymer is cast into silicone molds with a ratio of 1.4 parts HDI to 1 part PETMP by weight. For the preparation of ZnO filled PTU substrates, the particles are stirred into the PETMP component for $15 \mathrm{~min}$ at a speed of $2000 \mathrm{rpm}$. Afterwards the HDI component is added. The complete mixture is degassed in a desiccator and cured at $85^{\circ} \mathrm{C}$ for 24 hours in an atmospheric furnace. After curing, the substrates are cut into the desired dimensions of $25 \mathrm{~mm} \cdot 25 \mathrm{~mm}$.

The particle content in the polymer was varied and with increasing amount more scattering is observed as can be seen in figure 2 .



Fig. 2.: Photos of PTU foils containing different amounts of t-ZnO particles.

\section{OLEDs on PTU foils with t-ZnO particles}

The substrate foils are first cleaned for $10 \mathrm{~min}$ in acetone and isopropanol supported by an ultrasonic treatment. After drying for 2 hours at $70^{\circ} \mathrm{C}$ a thin gold layer with a thickness of $8 \mathrm{~nm}$ is evaporated as semitransparent anode. The samples are then treated with an oxygen plasma of $100 \mathrm{~W}$ for $40 \mathrm{sec}$ to ease the subsequent spincoating of lowconductive PEDOT:PSS (Sigma Aldrich) at $3500 \mathrm{rpm}$. Afterwards the foils are dried for 35 hours at $70^{\circ} \mathrm{C}$ under a pure nitrogen environment. Then $10 \mathrm{~nm}$ of molybdenum trioxide $\left(\mathrm{MoO}_{3}\right), 30 \mathrm{~nm}$ of $N, N^{\prime}$-Bis(naphthalen-1-yl)- $N, N^{\prime}-$ bis(phenyl)benzidine (NPB), $50 \mathrm{~nm}$ of Tris-(8-hydroxyquinoline)aluminum (Alq3) and finally 1nm lithium fluoride and $200 \mathrm{~nm}$ aluminium are thermally evaporated onto the samples to obtain a simple OLED as depicted in figure 3. For testing purposes the devices are encapsulated with another PTU foil and epoxy adhesive.

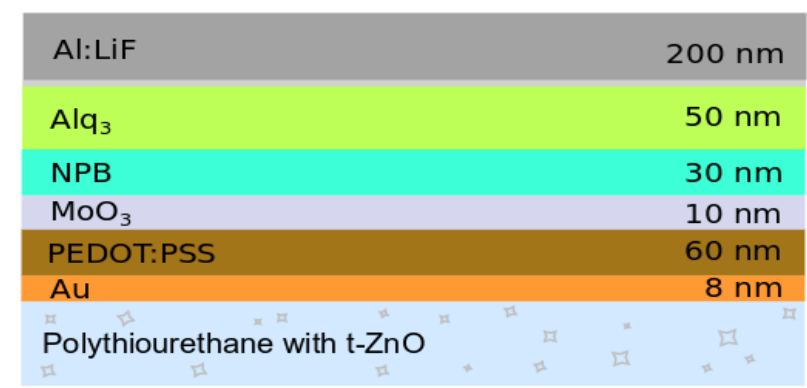

Fig. 3. OLED stack fabricated on PTU substrate.

The produced OLEDs without t-ZnO show a normal current-voltage behavior as can be seen in figure 4. The devices on t-ZnO containing substrates behave in an equal manner except from some sudden higher current consumption at lower voltages, which might appear due to an increased surface roughness with a higher particle content. The enlarged surface roughness was measured by confocal microscopy and is mainly an effect of the fully hand-made process of the foil production. Operation of the OLEDs under bending conditions is demonstrated successfully. 

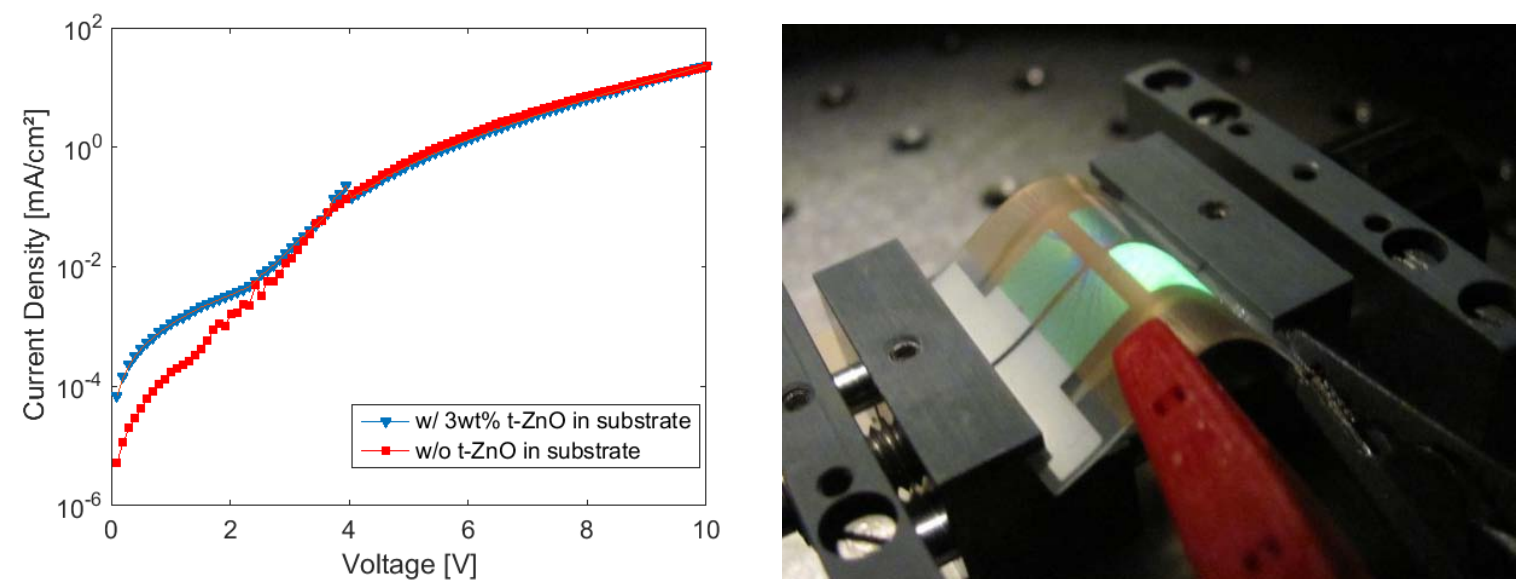

Fig. 4. Left: Current density-voltage diagram of fabricated OLEDs; Right: OLED on flexible PTU foil with 0,1wt\% t-ZnO.

\section{Conclusion}

Different amounts of t-ZnO particles were integrated into a PTU foil, which showed an increasing scattering effect with growing particle content. The foils were then successfully used as substrates for OLEDs. As the PTU polymer is comparatively UV stable, the produced foils are also promising for being used as substrates for organic photodiodes or other flexible solar cells.

\section{Acknowledgements}

The authors gratefully acknowledge the support by the European Fonds for Regional Development in the Interreg project "RollFlex". M.B., M.K., and M.G. acknowledge support by the ERC within the "PhotoSmart" project (Starting Grant Agreement 307800).

[1] S. Reineke, F. Lindner, G. Schwartz, N. Seidler, K. Walzer, B. Lüssem, and K. Leo, "White organic light-emitting diodes with fluorescent tube efficiency,” Nature 459, 234-238 (2009).

[2] Z. B. Wang, M. G. Helander, J. Qiu, D. P. Puzzo, M. T. Greiner, Z. M. Hudson, S. Wang, Z. W. Liu, and Z. H. Lu, "Unlocking the full potential of organic light-emitting diodes on flexible plastic,” Nat. Photonics 5, 753-757 (2011).

[3] W. Brütting, J. Frischeisen, T.D. Schmidt, B. J. Scholz, and C. Mayr, "Device efficiency of organic light-emitting diodes: Progress by improved light outcoupling,” Phys. Status Solidi A 210(1), 44-65 (2013).

[4] H.-W. Chang, J. Lee, S. Hofmann, Y. Y. Kim, L. Müller-Meskamp, B. Lüssem, C.-C. Wu, K. Leo, and Malte C. Gather, "Nano-particle based scattering layers for optical efficiency enhancement of organic light-emitting diodes and organic solar cells,” J. Appl. Phys. 113, 204502 (2013).

[5] L. Li, J. Liang, S. Chou, X. Zhu, X. Niu, Z. Yu, and Q. Pei, “A Solution Processed Flexible Nanocomposite with Efficient Light Extraction for Organic Light Emitting Diodes,” Sci. Rep. 4, 4307 (2014).

[6] L. Xu, Y.-L. Hu, C. Pelligra, C.-Hu Chen, L. Jin, H. Huang, S. Sithambaram, M.Aindow, R. Joesten, S. L. Suib, “ ZnO with different morphologies synthesized by solvothermal methods for enhanced photocatalytic activity,” ACS Chem. Mater. 21, 2875-2885 (2009)

[7] Y. K. Mishra, S. Kaps, A. Schuchardt, I. Paulowicz, X. Jin, D. Gedamu, S. Freitag, M. Claus, S. Wille, A. Kovalev, S. N. Gorb and R. Adelung, "Fabrication of Macroscopically Flexible and Highly Porous 3D Semiconductor Networks from Interpenetrating Nanostructures by a Simple Flame Transport Approach,” Part. Part. Syst. Charact. 30(9), 775-783 (2013).

[8] Y. K. Mishra, G. Modi, V. Cretu, V. Postica, O. Lupan, T. Reimer, I. Paulowicz,V. Hrkac, W. Benecke, L. Kienle, and R. Adelung. "Direct growth of freestanding ZnO tetrapod networks for multifunctional applications in photocatalysis, UV photodetection, and gas sensing," ACS Appl. Mater. Interfaces 7(26), 14303-14316 (2015).

[9] I. Hölken, M. Hoppe, Y. K. Mishra, S. N. Gorb, R. Adelung, and M. Baum. "Complex shaped zno nano- and microstructure based polymer composites: Mechanically stable and environmentally friendly coatings for potential antifouling applications." Phys. Chem. Chem. Phys. 18, 7114-7123 (2016). 